\section{Vertical Distribution of Crop Load and Fruit Quality within Vase- and Y-shaped Canopies of 'Elegant Lady' Peach}

\author{
Vittorio Farina, Riccardo Lo Bianco, ${ }^{1}$ and Paolo Inglese \\ Dipartimento di Colture Arboree, Università degli Studi di Palermo, Viale \\ delle Scienze 11, 90128 Palermo, Italy
} Additional index words. canopy layer, light interception, fruit size, product variability,
training form

\begin{abstract}
Canopy shape and depth may influence crop uniformity of peach trees at harvest. To test this hypothesis we examined yield distribution and fruit quality changes at different canopy levels of peach trees trained to delayed vase (DV) and perpendicular Y (Y). Trees of both training forms were divided vertically into six or seven $50-\mathrm{cm}$-deep layers and fruit was harvested at commercial ripening from each layer separately. Regardless of training form, number of fruit and yield per layer were highest in the central part of the canopy, but more evenly distributed among canopy layers in Y trees. In DV trees, fruit weight decreased linearly from top to bottom, whereas it remained constant along the top and middle portion of Y canopies to decrease rapidly at the bottom. In DV trees, $83 \%$ of the fruit fell into AAA, AA and A size categories, whereas fruit of $Y$ trees was more evenly distributed among all size categories. Hue of fruit peel color increased linearly with distance from canopy top in both training forms, but more sharply in DV trees. Fruit soluble solid content decreased linearly from canopy top to bottom, regardless of training form. A more uniform crop load distribution within the canopy in combination with a light penetration gradient resulted in greater variability of quality parameters for $Y$ than DV trees.
\end{abstract}

In peach [Prunus persica $(\mathrm{L}$.$) Batsch], fruit$ size, along with other fruit quality parameters, represents one of the major sources of fruit variability at harvest (Dann and Jerie, 1988; Genard and Bruchou, 1992). Final fruit size is the result of competition within the tree (Chalmers and Van den Ende, 1975) and depends on the position of the fruit within the canopy (Loreti et al., 1980; Tustin et al., 1988) and on the shoot (Spencer and Couvillon, 1975). Other sources of variability in peach fruit quality are represented by red peel color, soluble solids, acidity and flesh firmness, which may change independently (Genard and Bruchou, 1992).

Light plays a critical role in the relationship between position within the canopy and final fruit quality. Indeed, fruit weight and sugar content(Barrit et al., 1987; Jackson et al., 1971; Loreti et al., 1980), fruit color (Erez and Flore, 1986), number of flowers and fruits (Ferree, 1980), fruit set (Tustin et al., 1988), and yields (Barrit et al., 1991) are proportional to light interception within the canopy. Orchard design and tree training form significantly affect light interception and distribution within the canopy. For example, Y-shaped peach canopies show greater light interception and better distribution than open vase or central spindle (De Salvador and DeJong, 1989).

In addition, causes other than light level within the canopy, such as endogenous differences related to fruit position, may also affect percent dry weight of the mesocarp or soluble solids (Dann and Jerie, 1988). In

Received for publication 20 Feb. 2004. Accepted for publication 12 Aug. 2004.

${ }^{1}$ To whom reprint requests should be addressed; e-mail rlb@unipa.it. about $3 \mathrm{~m}$ and yielded $54 \mathrm{~kg} /$ tree $\left(27 \mathrm{t} \cdot \mathrm{ha}^{-1}\right)$; $\mathrm{Y}$ trees were kept at a height of about $3.5 \mathrm{~m}$ and yielded $46 \mathrm{~kg} /$ tree $\left(37 \mathrm{t} \cdot \mathrm{ha}^{-1}\right)$. Routine horticultural care (pruning, thinning, irrigation, fertilization, and pest control) was applied to all trees throughout the season. Fruit from both training systems were thinned approximately 30 days after full bloom by removing doubles and leaving about one fruit every $15 \mathrm{~cm}$ of shoot. In addition, DV trees were summer pruned once at the beginning of July, whereas Y trees were pruned in April, immediately after fruit thinning, and again in July (to remove suckers and young sprouts from the shoulder of the main branches).

Light interception was measured with LI190SZ Quantum sensors (LI-COR, Lincoln, Neb.) connected to a CR10 datalogger (Campbell Scientific Ltd., Logan, Ut.) and positioned within the canopy at $0.75,1.5$, and $2.25 \mathrm{~m}$ from the ground level as well as at canopy top. Light interception at each level was recorded as an average of three measurements over two days (1 and 2 Aug. 2001) and expressed as percentage of the incident (at canopy top) photosynthetic photon flux density (PPFD). Minimum percentage of incident PPFD and its location within the canopy were obtained using the algebraic expression for the vertex of the parabola (quadratic model) that best fitted the light data for each training form.

Tree canopies were divided vertically into 6 (DV) or 7 (Y) 50-cm-deep layers with the aid of a measuring pole, and all fruit was harvested by hand in 4 (Y) or 5 (DV) picks from 18 July to 3 Aug. 2001 according to ground color and flesh firmness. Fruit was placed in separate plastic bags and taken to the laboratory for determination of number, weight, diameter, color, flesh firmness, and soluble solid content (SSC). Percentage of red color was visually rated, whereas intensity of red color was measured with a colorimeter (CR-300; Minolta Co., Ltd., Osaka, Japan). Commission Internationale de l'Eclairage color space coordinates $\mathrm{L}^{*}, \mathrm{a}^{*}$, and $\mathrm{b}^{*}$ were used to calculate chroma $\left(C^{*}\right)$, an index of color saturation, and hue angle $\left(h^{\circ}\right)$ (McGuire, 1992). Flesh firmness was measured with a manual pressure tester (TR di Turoni \& Co., Forlì, Italy) mounting an 8-mm tip on two opposite peeled sides of the fruit, whereas SSC was measured with an Atago Palette PR-32 digital refractometer (Atago Co., Ltd., Tokyo, Japan). Weight and diameter were determined on each fruit and used to calculate yield and commercial size, respectively. Commercial sizes were AAA (>82.5 mm), AA (72.6 to $82.5 \mathrm{~mm})$, A (67.6 to $72.5 \mathrm{~mm}), \mathrm{B}(62.6$ to $67.5 \mathrm{~mm}), \mathrm{C}(57.6$ to $62.5 \mathrm{~mm})$, and $\mathrm{D}(<57.5 \mathrm{~mm})$. Peel color, flesh firmness, and SSC were determined on a sample of 40 to 50 fruit per training form $\times$ tree $\times$ layer combination when available, on all fruit for those layers where fewer peaches were present. The trunk circumference of each tree was measured at about $15 \mathrm{~cm}$ above the ground to calculate yield efficiency, expressed as kilograms of fruit per square centimeter of trunk cross-sectional area, and crop density, expressed as number of fruit per square centimeter of trunk cross-sectional area. 
Fig. 1. Percentage of incident photosynthetic photon flux density (PPFD) within canopies of 'Elegant Lady' peach trees trained to delayed vase (DV) and perpendicular $\mathrm{Y}(\mathrm{Y})$. For $\mathrm{Y}$ trees, $\mathrm{PPFD}=$ $99.8-68.4 \times$ distance $+14.7 \times$ distance $^{2}, r^{2}=$ 0.99 . For DV trees, $\mathrm{PPFD}=99.5-84 \cdot$ distance

$+21.3 \times$ distance $^{2}, r^{2}=0.99$.

Differences in yield, yield efficiency, and crop density between the two training forms were tested using Student's $t$ test, whereas differences in SSC between the two training forms were tested using analysis of variance and yield efficiency or crop density as a covariate (SYSTAT, SPSS, Inc., Chicago, Ill.). Means for each layer were plotted against distance from canopy top taken at the center of each layer. Regression analysis (SigmaPlot, SPSS Inc., Chicago, Ill.) was used to determine association between distance from canopy top and parameters observed. All coefficients presented in regression models are significant at $P \leq 0.05$ and the best model for each set of data was chosen based on the Schwarz's Bayesian criterion (SBC).

\section{Results and Discussion}

Yield (54 and $46 \mathrm{~kg} /$ tree for DV and Y, respectively), yield efficiency ( 0.38 and 0.41 $\mathrm{kg} \cdot \mathrm{cm}^{-2}$ for DV and Y, respectively), and crop density (2.17 and 2.36 fruit $/ \mathrm{cm}^{2}$ for DV and $\mathrm{Y}$, respectively) were similar $(P>0.05)$ for both training forms. Percentage of incident PPFD decreased from canopy top to bottom in a quadratic manner for both training forms, but more sharply in DV than Y trees as shown by the more negative linear coefficient $(P=$ 0.033 ) for the model associated with DV trees (Fig. 1). Moreover, minimum light interception was $20.2 \%$ of incident PPFD and occurred at $2.33 \mathrm{~m}$ from the canopy top in $\mathrm{Y}$ trees, and $16.7 \%$ of incident PPFD at $1.97 \mathrm{~m}$ from the canopy top in DV trees. Similar light interception data have been reported in apple (Ferree et al., 1980; Tustin et al., 1988) and in peach trees trained to vase (Chalmers et al., 1975) and Y (Caruso et al., 1998). Those light level differences within the canopies indicate that $Y$ trees, despite having a taller canopy, are more efficient in terms of light distribution within the canopy than DV trees, in agreement with the data of De Salvador and DeJong (1989). These differences could be partly due to more frequent and efficient pruning of Y trees during the vegetative season.

Number of fruit and yield per layer followed similar quadratic trends for the two training forms and were greatest in the central portion of the canopy (Fig. 2A and B). However, number of fruit and yield were more uniformly distributed throughout $Y$ than DV canopies, as shown by the significantly smaller $(P=0.025)$

Fig. 2. Number of fruit (A) and yield (B) distribution within canopies of 'Elegant Lady' peach trees trained to delayed vase (DV) and perpendicularY (Y). For $\mathrm{Y}$ trees, $\mathrm{N} \times$ fruit $=84 \times$ distance $-25 \times$ distance ${ }^{2}, r^{2}=0.90 ;$ yield $=14.1 \times$ distance -4.4 $\times$ distance $^{2}, r^{2}=0.89$. For DV trees, N. fruit $=$ $166 \times$ distance $-52 \times$ distance $^{2}, r^{2}=0.91$; yield $=30.5 \times$ distance $-9.6 \times$ distance $^{2}, r^{2}=0.91$.
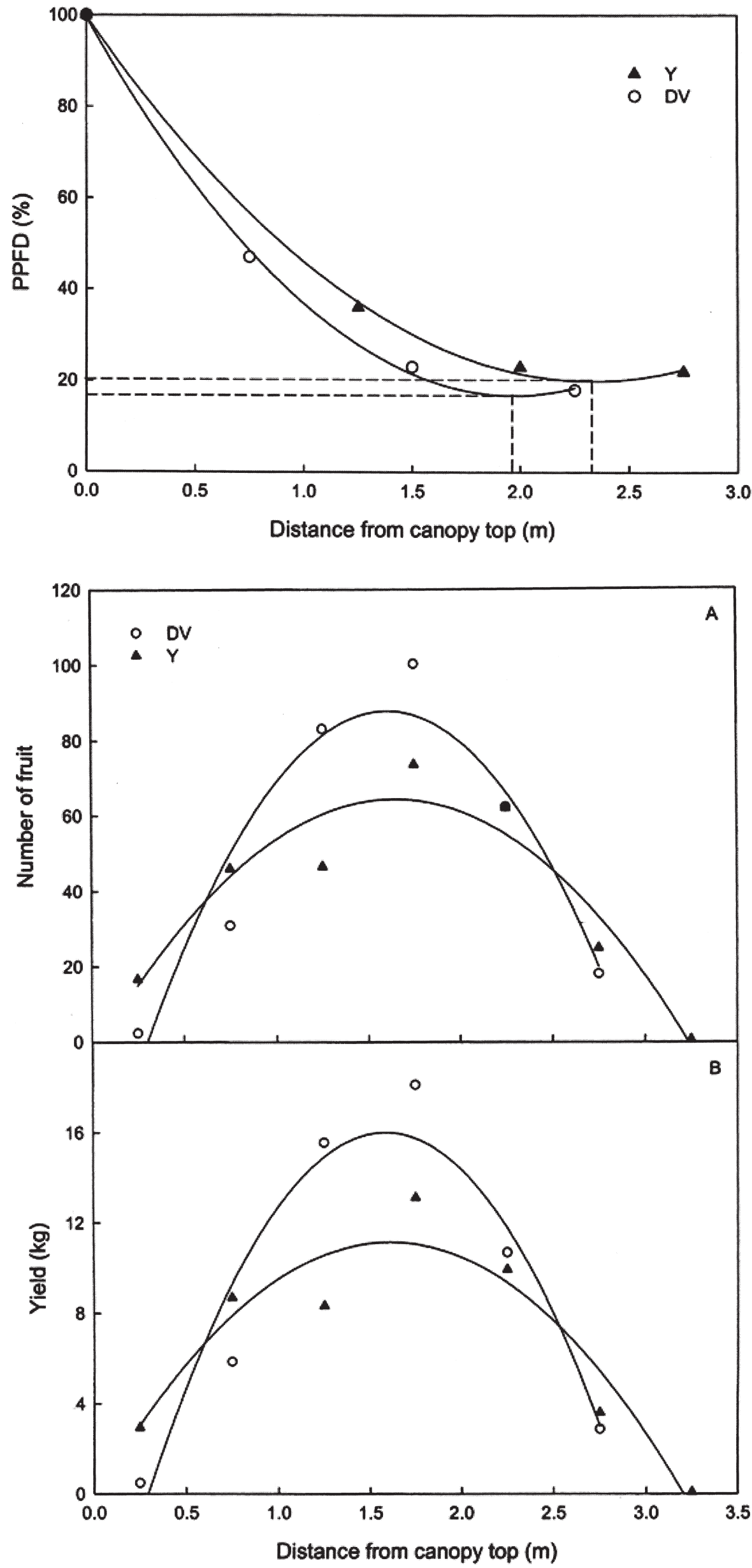


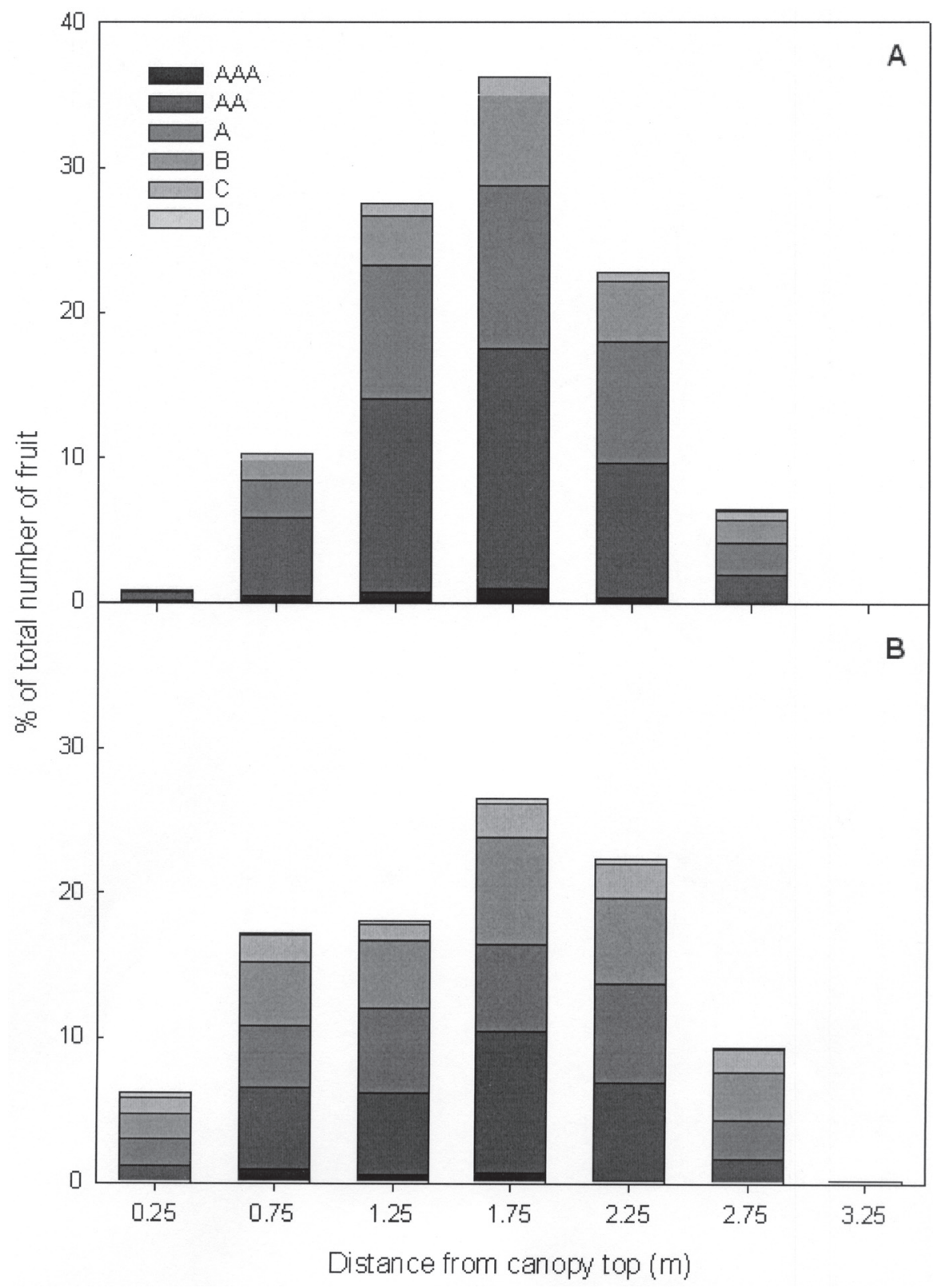

Fig. 3. Distribution of fruit size categories within canopies of 'ElegantLady'peach trees trained to delayed vase (DV) (A) and perpendicular Y (Y) (B).

quadratic coefficient (indicating a lower degree of curvature). These differences are associated with a greater number of bearing shoots in the central portion of each main limb in DV trees compared to $\mathrm{Y}$ trees, which may be due to a difference in pruning of 1-year-old and older wood and the resulting light penetration within the two training forms.

Of the fruit produced on DV trees, $83 \%$ was distributed among size categories AAA, $\mathrm{AA}$ and $\mathrm{A}$, and located primarily $(52 \%)$ in the central portion of the canopy (Fig. 3A), whereas only $61 \%$ of the fruit produced on $Y$ trees fell into size categories AAA, AA, and A (Fig. 3B). Caruso et al. (1998) reported that $\mathrm{Y}$ trees produced a greater number of large-sized fruit than did trees trained to central leader.

Fruit weight decreased from canopy top to bottom in both training forms (Fig. 4A). This

decrease may be, in part, associated with light interception. Similar findings are reported for apple (Robinson et al., 1983) and peach (Caruso et al. 1998; Marini et al., 1991) trees. Yet, fruit weight of DV trees decreased linearly as distance from canopy top increased, whereas fruit weight of Y trees remained nearly constant in the upper and central portions of the canopy and decreased rapidly in the lower levels. This difference in fruit weight at various canopy locations could be associated with longer bearing shoots, and therefore higher leaf:fruit ratios, at the top of DV canopies compared to Y canopies.

Although peaches were harvested at commercial ripening based on ground color and flesh firmness, significant changes in flesh firmness were observed throughout the canopy of both training forms. Specifically, in DV trees fruitflesh firmness followed a polynomial trend with its vertex in the central portion of the canopy, whereas in Y trees firmness decreased linearly from top to bottom (Fig. 4B). Atharvest workers are often influenced by fruit size and 


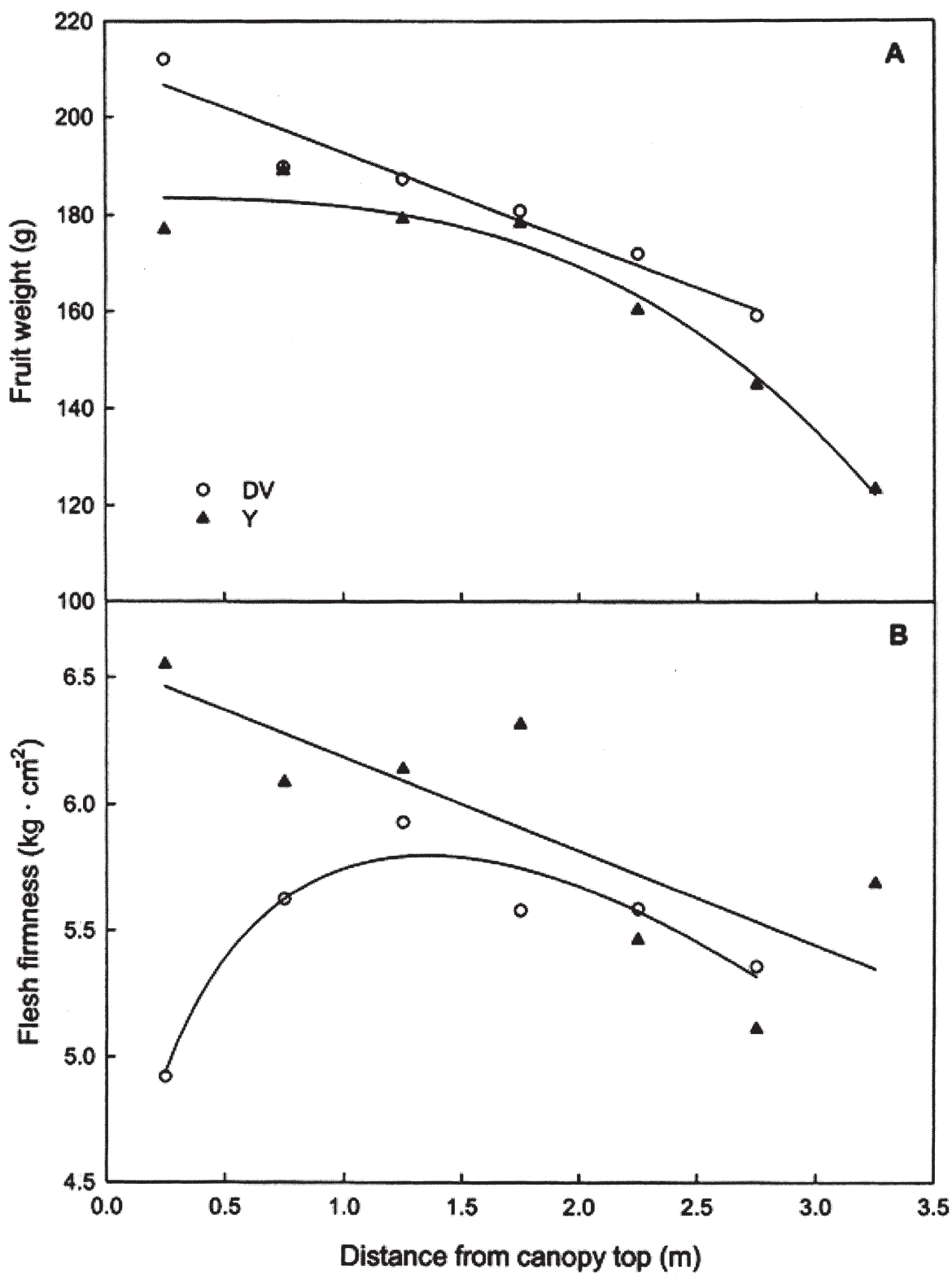

red color, which could result in the delayed harvest of less colored fruit at the bottom of the canopy. This may explain the proportional decrease in flesh firmness from top to bottom in Y trees. Also, fruit of the taller Y trees was picked with the help of harvesting trailers, whereas fruit of the DV trees were harvested from the ground. Thus, fruit at the top of DV canopies may have remained on the tree for longer and consequently lost firmness.

The $\mathrm{H}^{\circ}$ value was proportional to distance from canopy top in both training forms (Fig. $5 \mathrm{~A})$. Specifically as the distance progressed from canopy top to bottom, fruit peel color shifted from red to orange. Similar results are reported for peach trees trained to modified central leader (Bible and Singha, 1993) and Y (Caruso et al., 1998). However, in our study the shift in $\mathrm{h}^{\circ}$ was greater for fruit of DV trees than those of $Y$ trees as shown by the sharper $(P=0.049)$ inclination of the line (Fig. 5A). Percent of red color, $L^{*}$, and $C^{*}$ did not follow any specific trend (data not shown).

Also SSC decreased linearly as distance from canopy top increased in both training

Fig. 4. Fruit weight (A) and flesh firmness (B) within canopies of 'Elegant Lady' peach trees trained to delayed vase (DV) and perpendicular $\mathrm{Y}(\mathrm{Y})$. For $Y$ trees, weight $=183-1.79 \times$ distance $^{3}, r^{2}=$ 0.96 ; firmness $=6.56-0.37 \times$ distance, $r^{2}=0.63$. For DV trees, weight $=211-18.6 \times$ distance, $r^{2}$ $=0.94 ;$ firmness $=3.15-1.96 \times$ distance +4.55 $\times$ distance $^{0.5}, r^{2}=0.91$.

forms (Fig. 5B). The slopes of the two lines, in this case, were similar, whereas the y-intercept for DV trees was significantly higher than the $\mathrm{y}$-intercept for $\mathrm{Y}$ trees $(P<0.001)$. In other words, fruit of DV trees were sweeter than that of Y trees at all canopy layers. These differences remained significant even following adjustment of SSC for crop load by using yield efficiency as a covariate. Similar decreasing trends from canopy top to bottom for SSC were reported by other Authors in peach (Caruso et al., 1998; Dann and Jerie, 1988; Génard and Bruchou, 1992) and apple (Tustin et al., 1988). Lower sugar content at the bottom of the canopy could be due to hormonal signals associated with fruit position (Chalmers, 1986); or, more likely, lower light interception at the 


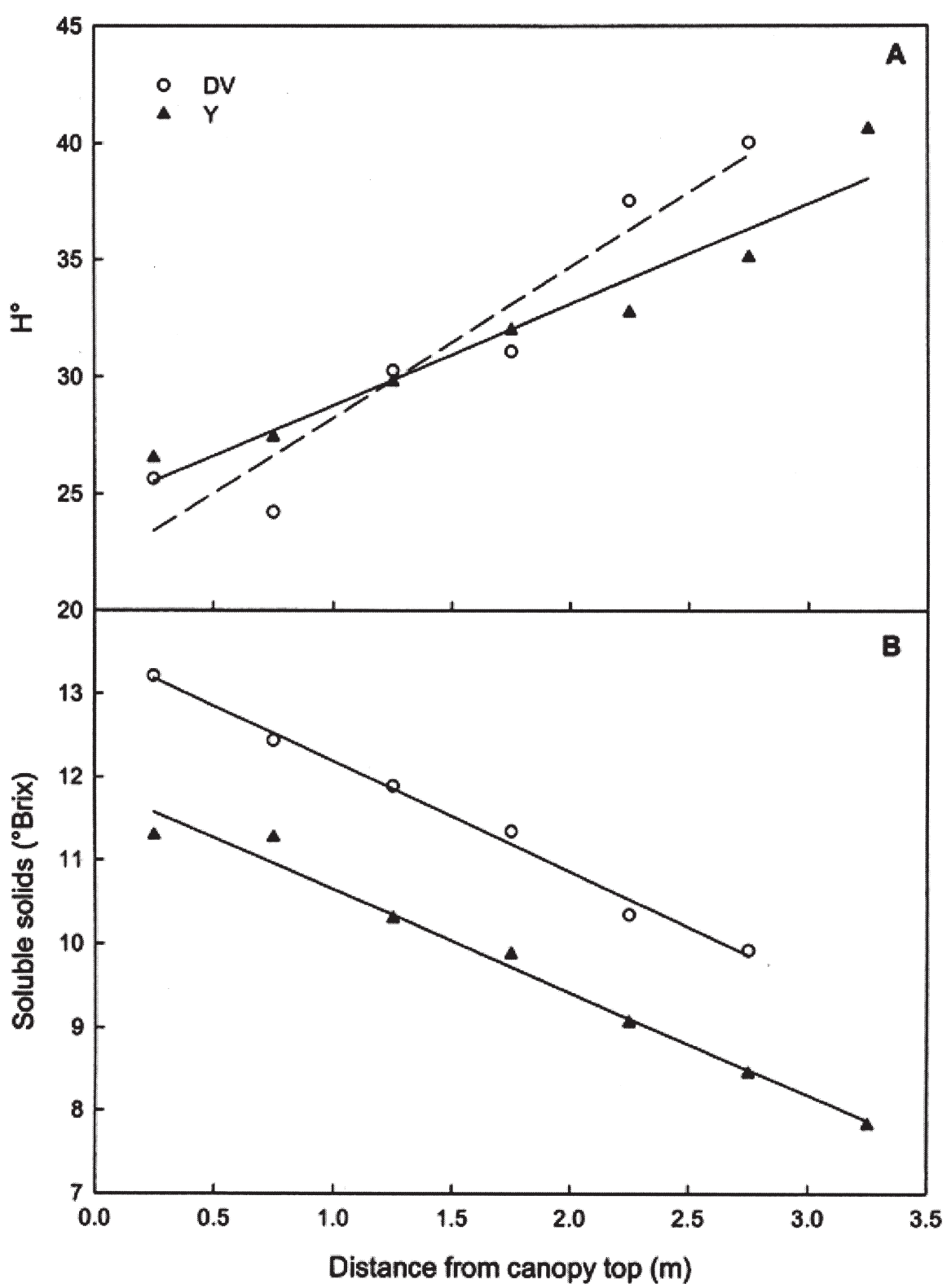

Fig. 5. Fruit hue (H) (A) and soluble solid content (SSC) (B) within canopies of 'Elegant Lady' peach trees trained to delayed vase (DV) and perpendicular $\mathrm{Y}(\mathrm{Y})$. For $\mathrm{Y}$ trees, $\mathrm{H}=24.5+$ $4.31 \times$ distance, $r^{2}=0.93 ; \mathrm{SSC}=11.9-1.23$ $\times$ distance, $r^{2}=0.98$. For DV trees, $\mathrm{H}=21.8+$ $6.44 \times$ distance, $r^{2}=0.92 ; \mathrm{SSC}=11.9-1.23 \times$ distance, $r^{2}=0.99$.

bottom of the canopy could reduce assimilate production and supply to the fruit, and in turn be responsible for lower sugar levels.

Position within the canopy had a major effect on peach fruit quality, due mainly to light penetration. Also, a more uniform crop load distribution among canopy layers in combination with a light penetration gradient (and perhaps
Caruso T., C. Di Vaio, P. Inglese, and L.S. Pace. 1998. Crop load and fruit quality distribution within canopy of 'Spring Lady' peach trees trained to 'central leader' and 'y shape'. Acta Hort. 465:621-628.

Chalmers, D.J. and B. van den Ende. 1975. Productivity of peach trees: Factors affecting dryweight distribution during tree growth. Ann. Bot. 39:423-432.

Corelli-Grappadelli, L. and D.C. Coston. 1991. Thinning pattern and light environment in peach tree canopies influence fruit quality. HortScience 26:1464-1466.

Corelli-Grappadelli, L., G. Ravaglia, and A. Asirelli. 1996. Shoot type and light exposure influence carbon partitioning in peach cv. Elegant Lady. J. Hort. Sci. 71:533-543.

Dann, I.R. and P.H. Jerie. 1988. Gradients in maturity and sugar levels of fruit within peach trees. J. Amer. Soc. Hort. Sci. 113:27-31.

De Salvador F.R. and T.M. DeJong. 1989. Observation of sunlight interception and penetration into the canopies of peach trees in different planting densities and pruning configurations. Acta Hort. 254:341-346.

ErezA. and J.A. Flore. 1986. The quantitative effect of solar radiation on 'Redhaven' peach fruit skin color. HortScience 21:1424-1426.

Ferree D.C. 1980. Canopy development and yield efficiency of 'Golden Delicious' apple trees in four orchard management systems. J.Amer. Soc. Hort. Sci. 105:376-380.

Genard, M. and C. Bruchou. 1992. Multivariate analysis of within-tree factors accounting for the variation of peach fruit quality. Sci. Hort. 52:37-51.

Jackson, J.E., R.O. Sharples, and J.W. Palmer. 1971. The influence of shade and within-tree position on apple fruit size, colour and storage quality. J. Hort. Sci. 46:277-287.

Loreti, F., S. Morini, and D. Stefanelli. 1980. Observation on sunlight interception and penetration into canopy of peach trees at different planting densities. Riv. Ortoflorofrutt. 64:315-323.

Marini R.P., D. Sowers, and C.M. Marini. 1991. Peach fruit quality is affected by shade during final swell of fruit growth. J. Amer. Soc. Hort. Sci. 116:383-389.

Marini R. and D.L. Sowers. 1994. Peach fruit weight is influenced by crop density and fruiting shoot length but not position on the shoot. J. Amer. Soc. Hort. Sci. 119:180-184.

McGuire, R.G. 1992. Reporting of objective color measurements. HortScience 27:1254-1255.

Robinson T.R., E.J. Seeley, and B.H. Barrit. 1983. Effect of light environment and spur age on 'Delicious' apple fruit size and quality. J. Amer. Soc. Hort. Sci. 108:855-861.

Barrit B.H., C.R. Rom, K.R. Guelish, S.R. Drake, and M.A. Dilley. 1987. Canopy position and light effects on spur, leaf, and fruit characteristics of 'Delicious' apple. HortScience 22:402-405.

Barrit B.H., C.R. Rom, B.J. Konishi, and M.A Dilley. 1991. Light level influences spur quality and canopy development and light interception influence fruit production in apple. HortScience 26:993-999.

Bible B. and S. Singha. 1993. Canopy position influences CIELAB coordinates of peach color. HortScience 28:992-993.
Spencer S. and G.A. Couvillon. 1975. The relationship of node position to bloom date, fruit size, and endosperm development of the peach, Prunus persica (L.) Batsch cv. Sullivan's Elberta. J. Amer. Soc. Hort. Sci. 100:242-244.

Tustin S.D., P.M. Hirst, and IJ. Warrington. 1988. Influence of orientation and position of fruiting laterals on canopy light penetration, yield, and fruit quality of 'Granny smith' apple. J. Amer. Soc. Hort. Sci. 113:693-699. 